Article

\title{
Acaulospora as the Dominant Arbuscular Mycorrhizal Fungi in Organic Lowland Rice Paddies Improves Phosphorus Availability in Soils
}

\author{
Khachonphong Nopphakat ${ }^{1,2}$, Phanthipha Runsaeng ${ }^{3}$ and Lompong Klinnawee ${ }^{1,2, *(D)}$ \\ 1 Division of Biological Science, Faculty of Science, Prince of Songkla University, Songkhla 90110, Thailand; \\ 6310220041@psu.ac.th \\ 2 Plant Cell and Physiology for Sustainable Agriculture Research Unit, Faculty of Science, Prince of Songkla \\ University, Songkhla 90110, Thailand \\ 3 Division of Health and Applied Sciences, Faculty of Science, Prince of Songkla University, \\ Songkhla 90110, Thailand; phanthipha.r@psu.ac.th \\ * Correspondence: lompong.k@psu.ac.th
}

Citation: Nopphakat, K.; Runsaeng, P.; Klinnawee, L. Acaulospora as the Dominant Arbuscular Mycorrhizal Fungi in Organic Lowland Rice Paddies Improves Phosphorus Availability in Soils. Sustainability 2022, 14, 31. https://doi.org/ $10.3390 /$ su14010031

Academic Editors: Othmane Merah, Purushothaman Chirakkuzhyil Abhilash, Magdi T. Abdelhamid, Hailin Zhang and Bachar Zebib

Received: 24 November 2021

Accepted: 17 December 2021

Published: 21 December 2021

Publisher's Note: MDPI stays neutral with regard to jurisdictional claims in published maps and institutional affiliations.

Copyright: (C) 2021 by the authors. Licensee MDPI, Basel, Switzerland. This article is an open access article distributed under the terms and conditions of the Creative Commons Attribution (CC BY) license (https:// creativecommons.org/licenses/by/ $4.0 /)$.

\begin{abstract}
Flooding in rainfed lowlands greatly impairs the mutualistic relationship between indigenous arbuscular mycorrhizal fungi (AMF) and rice. In flooded soils, root colonization by AMF is arrested, but some AMF genera, defined as the core AMF, remain present. However, the core AMF in rainfed lowlands and their symbiotic roles remain unknown. Here, we showed that Acaulospora fungi were the core AMF in rice seedling roots of the Sangyod Muang Phatthalung (SMP) landrace rice variety grown in non-flooded and flooded paddy soils. Subsequently, indigenous Acaulospora spores were propagated by trap cultures using maize as the host plants. Therefore, to clarify the roles of cultured Acaulospora spores in a symbiotic partnership, the model japonica rice variety Nipponbare was grown in sterile soil inoculated with Acaulospora spores, and recolonized with a native microbial filtrate from the organic rice paddy soil. Our data demonstrated that the inoculation of Acaulospora spores in well-drained soil under a nutrient-sufficient condition for six weeks enabled 70 percent of the rice roots to be colonized by the fungi, leading to higher phosphate $(\mathrm{Pi})$ accumulation in the mycorrhizal roots. Unexpectedly, the growth of rice seedlings was significantly suppressed by inoculation while photosynthetic parameters such as fractions of incoming light energy and relative chlorophyll content were unaltered. In the soil, the Acaulospora fungi increased soil phosphorus (P) availability by enhancing the secretion of acid phosphatase in the mycorrhizal roots. The findings of this work elucidate the symbiotic roles of the dominant Acaulospora fungi from lowland rice paddies.
\end{abstract}

Keywords: arbuscular mycorrhizal fungi; Acaulospora; soil phosphorus availability

\section{Introduction}

Rice forms a mutualistic relationship with AMF to deal with nutrient deficiencies in soils, especially P. AMF symbiosis increases P acquisition efficiency through the mycorrhizal uptake pathway in roots, leading to higher P uptake in shoot and root tissues [1]. Under well-drained soil, external phosphorus availability is the major factor regulating AMF symbiosis in rice [2]. However, in lowland rice paddies, water is irrigated and/or rainfed, enabling the cultivation of rice plants in mostly flooded soil [3]. The flooded condition induces the formation of aerenchyma in the root cortex, reducing the accommodation of AMF and the degree of AMF symbiosis in rice roots [4]. Moreover, flooding displays a stronger impact on the intensity of AMF colonization than soil $P$ availability [2,5].

Although AMF symbiosis is restricted by flooding, it remains sustained in paddies of lowland rice. While AMF colonization in roots of upland rice is well developed, with an increasing amount of mature arbuscules and intracellular hyphae, colonization in roots of lowland rice is scarcely present [6]. The colonization rate of indigenous AMF in roots is in the range of 0 to 40 percent, depending on the growth and developmental stage of 
the plant [7-9]. Moreover, flooding markedly reduces AMF species richness, diversity and abundance in rice roots [6]. As indicated by the reduction of mycorrhizal growth responses [10], the role of AMF symbiosis is minimized by flooding in lowland rice paddies, but the remaining AMF still contribute sufficient direct and/or indirect benefits to the host plants.

AMF act as soil P improvers. AMF symbiosis assists the host plants to assimilate $\mathrm{P}$ derived from unavailable forms such as organic $\mathrm{P}$ and precipitated $\mathrm{P}$ by increasing $\mathrm{P}$ mineralization in the soil [11]. AMF are capable of secreting acid phosphatase and phytase from extraradical hyphae to the surrounding soils, where they convert unavailable organic $\mathrm{P}$ and phytate, respectively, into inorganic $\mathrm{P}$ available for uptake in rice plant roots $[12,13]$. AMF prevent $P$ and nitrogen losses in rice paddies by reducing nutrient leaching and runoff from the soil $[14,15]$. In addition to improving nutrient acquisition efficiency in rice paddies, applied AMF enhance the resilience of rice to environmental stresses in paddies, such as drought, salt and heavy metals $[16,17]$. However, the AMF used in previous studies, such as Funneliformis mosseae and Rhizophagus intraradices, belong to the family Glomaceae. They are present in lowland rice paddies [7] but in some areas they may be absent or not the dominant AMF species due to their relatively low abundance $[8,18]$.

Diversity of indigenous AMF in rice paddies is dependent on the rice ecosystem and water management $[6,8]$. Glomus and Funneliformis AMF genera are ubiquitously present in most upland and lowland rice paddies [6,18]. Paraglomus and Claroideoglomus were reported as the second most abundant AMF in upland rice paddies $[19,20]$. In several lowland rice paddies, Acaulospora is the most dominant AMF genus [18,20]. However, little is known about the symbiotic role of Acaulospora fungi in rice, especially the native Acaulospora species in lowland rice paddies.

Our previous study showed that flooding plays a major role in shaping fungal communities and significantly reduced AMF colonization and AMF abundance in the roots of the $\mathrm{SMP}$ landrace rice variety grown in organic rice paddy soil. Only eight amplicon sequence variants of the fungal ITS sequences belonged Glomeraceae, which seems to underestimate the total AMF species in the study site [5]. Moreover, the molecular identification of AMF at the genus or species level by the ITS region is limited. Therefore, in this study, the $1.5 \mathrm{~kb}$ SSU-ITS-LSU region generated by the Krüger primers was further analyzed to identify the core AMF in the SMP roots under non-flooded and flooded soils. Later, we attempted to culture the core AMF to characterize its mutualistic functions in the model japonica rice variety Nipponbare. We expected the indigenous core AMF cultured from organic lowland rice paddy soil to promote the growth of the host plants, and potentially be useful for improving organic rice cultivation in lowland rice paddies.

\section{Materials and Methods}

\subsection{Determination of AMF in Rice Roots}

Genomic DNA samples of roots of Sangyod Muang Phatthalung (SMP) rice plants grown in non-flooded and flooded conditions for 6 weeks were obtained from our previous study [5]. To identify the 1.5-kb SSU-ITS-LSU sequences of AMF present in the roots, nested PCR was run with Kruger primers [21]. The primary run was performed using a $25 \mu \mathrm{L}$ reaction containing $50 \mathrm{ng}$ of root gDNA, 1xPhusion HF buffer, $0.2 \mathrm{mM}$ dNTPs mixture, $0.5 \mu \mathrm{M}$ of the forward and reverse primers, and 0.25 unit of Phusion high-fidelity DNA polymerase (Thermo Fisher Scientific, Waltham, MA, USA). The primary PCR condition was programmed as follows: Initial denaturation at $98^{\circ} \mathrm{C}$ for $30 \mathrm{~s}$ followed by 35 cycles of a 3 step PCR including denaturation at $98^{\circ} \mathrm{C}$ for $10 \mathrm{~s}$, annealing at $60^{\circ} \mathrm{C}$ for $30 \mathrm{~s}$ and extension at $72{ }^{\circ} \mathrm{C}$ for $1 \mathrm{~min}$. The reaction was completed with a final extension at $72{ }^{\circ} \mathrm{C}$ for $10 \mathrm{~min}$. The PCR product was diluted 1:50 and used as the DNA template in the secondary PCR. The second run used a $25 \mu \mathrm{L}$ reaction containing $1 X$ ViBuffer S, $0.1 \mathrm{mM}$ dNTPs mix, $0.4 \mu \mathrm{M}$ each of forward and reverse primers, and 1 unit of Tag DNA polymerase (Vivantis, Shah Alam, Malaysia). The secondary PCR was carried out under the following conditions: 2 min initial denaturation at $94{ }^{\circ} \mathrm{C}, 30$ cycles of $30 \mathrm{~s}$ denaturation at $94{ }^{\circ} \mathrm{C}, 30 \mathrm{~s}$ annealing at 
$60{ }^{\circ} \mathrm{C}, 2$ min elongation at $72{ }^{\circ} \mathrm{C}$ and $7 \mathrm{~min}$ final elongation at $72{ }^{\circ} \mathrm{C}$. $\mathrm{PCR}$ products were visualized by $1 \%$ agarose gel electrophoresis under UV light.

The PCR products were purified by a QIAquick gel purification kit (Qiagen, Hilden, Germany). Equal amounts of six purified PCR products from roots grown under the same condition were pooled into a single sample, ligated using the pGEM-T Easy vector (Promega, Madison, WI, USA) and transformed in E. coli DH5 $\alpha$. Sixty genuine transformants were selected by colony PCR using the M13 forward and reverse primers. Plasmids were extracted with the PrestoTM Mini Plasmid kit (Geneaid, New Taipei, Taiwan) and sequenced.

120 SSU-ITS-LSU sequences of AMF were aligned by Clustal Omega [22] and clustered into different operational taxonomic units (OTUs) at a 97\% identity threshold using the adegenet [23] and kmer [24] packages in the statistical software $\mathrm{R}$ (version 3.6.3). Rarefaction curves were constructed by the vegan package [25] in $R$ to determine whether the obtained clones sufficiently represented Glomeromycotean diversity in the rice root endophere under the non-flooded and flooded conditions.

The representative AMF OTUs were blasted in the NCBI database. Clustal Omega [22] was used to align the 21 AMF OTUs, 20 AMF reference sequences from the NCBI and MaarjAM databases and two sequences of Chaetomium globosum and Myrothecium sp. as outgroups. A neighbor-joining tree (Kimura 2 parameters, 1000 replications) was constructed using the MEGA software version 10 [26]. Sequences from this study were made available in the GenBank under accession numbers OL662890, OL672273-OL672310, OL672756OL672834, OL679926 and OL679961.

\subsection{Determination of AMF Diversity in Rice Roots}

The frequency of sequences in each AMF OTU was collected. The richness, diversity, and evenness of AMF OTUs were compared between the non-flooded and flooded conditions. Shannon's $\left(\mathrm{H}^{\prime}\right)$ diversity index within the same soil condition was calculated following the formula: $H^{\prime}=-\sum_{i=1}^{n} p i \ln p i$ where $n$ is the total number of OTUs and $p i$ is the proportion of sequences belonging to each OTU relative to the total number of sequences. AMF OTU evenness was calculated by dividing Shannon's diversity index $\mathrm{H}$ by the natural logarithm of species richness, $\ln (\mathrm{s})$, using Microsoft Excel.

\subsection{Trap Culture}

In a pot $20 \mathrm{~cm}$ in height and $24 \mathrm{~cm}$ in diameter, the same batch of organic paddy soil used in our previous study [5] was mixed 1:3 $(v / v)$ with sterile sand to be used for a trap culture using maize as the host plant. Acaulospora spores were isolated by the wet sieving and decanting method [27] and used to obtain a monospore culture. For the monospore culture, 300 Acaulospora spores were inoculated in four maize plants in the mixture of sterile sand and compost at a ratio of 1:1 $(v / v)$ in a 1-L pot $12 \mathrm{~cm}$ in height and $14 \mathrm{~cm}$ in diameter. The culture was recolonized with $100 \mathrm{~mL}$ of a microbial wash, prepared from $50 \mathrm{~g}$ of the paddy soil suspended in $1 \mathrm{~L}$ of distilled water and filtered 3 times with Whatman no.1 paper. The trap culture was fertilized with 0.5X Hoagland's solution twice a week and watered daily with tap water for 10 weeks and later air-dried for 2 weeks in a greenhouse to complete the trap culture.

\subsection{Identification of Cultured AMF Spores}

The Acaulospora spores were permanently mounted in polyvinyl alcohol-lactic acidglycerol (PVLG) solution with and without Melzer's reagent and visualized under a microscope. Ten spores were crushed in $5 \mu \mathrm{L}$ of $1 x$ Phusion HF buffer by a pipette tip and heated at $95{ }^{\circ} \mathrm{C}$ for $5 \mathrm{~min}$. The supernatant was used for the nested PCR and transformation as previously described. Ten SSU-ITS-LSU sequences from the spores were individually annotated in the NCBI database. The ten sequences from the spores and the representative Acaulospora OTUs (OTU11-21) were used to calculate sequence similarity with the seqinr package [28] in R to confirm the presence of cultured Acaulospora fungi in the roots grown 
in the indigenous rice paddy soil. The percent similarity was demonstrated in a heatmap by the pheatmap package [29] in R. Sequences of Acaulospora spores from this study were made available in the GenBank under accession numbers OL661631 to OL661640.

\subsection{Experimental Design for Determination the Role of Acaulospora fungi in Rice Seedling}

Seeds of Oryza sativa subsp. japonica cv. Nipponbare were kindly provided by Prof. Dr. Supachitra Chadchawan, Chulalongkorn University, Thailand. Rice seedlings were grown in $1 \mathrm{~L}$ pots containing the sterile compost and sand mix, recolonized with the microbial wash described above. Each pot contained five plants. Soil was added with and without the Acaulospora AMF inoculum containing 1000 spores ( $n=5$ biological replicates), and five pots containing the non-inoculated soil without rice seedlings were prepared as a blank treatment to analyze the soil P status at the end of the experiment. All of the treatments were fertilized twice a week with $200 \mathrm{~mL}$ of $0.5 \times$ Hoagland's solution and watered daily with $200 \mathrm{~mL}$ of distilled water for 6 weeks.

\subsection{Analysis of Soil Properties}

Soil from pots in the blank treatment ( $\mathrm{n}=5$ biological replicates) was collected to analyse soil properties. Soil organic matter was determined by the titration method [30]. Total $\mathrm{N}$ was determined by the combustion method using a C/N analyzer CN628 (LECO, Thailand). Total $\mathrm{P}$ and available $\mathrm{P}$ were determined by the Molybdovanadophosphate method using a spectrophotometer (Prove 300, Merck KGaA, Darmstadt, Germany) [31,32]. Total $\mathrm{K}$ was determined by the flame photometric method using inductively coupled plasma optical emission spectrometry (ICP-OES) (Avio 500, Perkin Elmer, Waltham, MA, USA) [33]. Soil $\mathrm{pH}$ and electrical conductivity were measured with a conductivity meter (Orion Star A112, Thermo Fisher Scientific, Waltham, MA, USA).

\subsection{Determination of Plant Growth Performance}

Photosynthetic parameters such as (Phi2), (PhiNPQ), (PhiNO) and relative chlorophyll content were measured in the first mature leaf of three rice seedlings in the same pot by the Photosynthesis RIDER protocol using the MultispeQ fluorometer (PhotosynQ, East Lansing, MI, USA) [34]. The three rice seedlings were dried at $70{ }^{\circ} \mathrm{C}$ for 3 days before measuring shoot and root dry weights.

\subsection{Determination of Pi Content in Rice Seedlings}

Soluble Pi in plant tissues was determined by a molybdenum blue-based quantitative assay [35]. Briefly, $10 \mathrm{mg}$ of the first mature leaf and $20 \mathrm{mg}$ of root from a rice seeding in each pot were ground in $600 \mu \mathrm{L}$ of $3 \%(v / v)$ perchloric acid. After centrifugation at $11,000 \mathrm{rpm}$ for $5 \mathrm{~min}$, the supernatant was collected and then mixed with $400 \mu \mathrm{L}$ of the assay reagent containing $1 \%(w / v)\left(\mathrm{NH}_{4}\right)_{6} \mathrm{Mo}_{24} \mathrm{O}_{24} \cdot 4 \mathrm{H}_{2} \mathrm{O}$ and $5 \%(w / v) \mathrm{FeSO}_{4} \cdot 7 \mathrm{H}_{2} \mathrm{O}$ in $1 \mathrm{~N} \mathrm{H}_{2} \mathrm{SO}_{4}$. After shaking followed by incubation for $10 \mathrm{~min}$, absorption at $720 \mathrm{~nm}$ was measured using a microplate reader (BIOTEX, PowerwaveX). The Pi content in each sample was calculated using a $\mathrm{KH}_{2} \mathrm{PO}_{4}(5-250 \mathrm{nmol} / \mathrm{mL}$ range $)$ standard.

\subsection{Determination of AMF Colonization}

Root cuttings measuring $1.5 \mathrm{~cm}$ were cleaned in $1 \mathrm{~mL}$ of $10 \%(w / v) \mathrm{KOH}$ at $95{ }^{\circ} \mathrm{C}$ for $15 \mathrm{~min}$. The roots were then rinsed with water and incubated in $1 \mathrm{~mL}$ of $1 \%(v / v)$ $\mathrm{HCl}$ at room temperature for $10 \mathrm{~min}$. After removal of the $\mathrm{HCl}$ solution, the samples were incubated overnight in $1 \mathrm{~mL}$ of Trypan blue staining solution containing $0.05 \%(w / v)$ Trypan blue, 33\% $(v / v)$ lactic acid and 33\% $(v / v)$ glycerol. The root samples were destained twice overnight in $1 \mathrm{~mL}$ of $50 \%(v / v)$ glycerol. Thirty root pieces were neatly placed on microscopic slides and mounted with $50 \%(v / v)$ glycerol. Five categories of mycorrhizal structures were quantified from 200 observations of roots under a light microscope at $100 \times$ magnification. The categories included (1) non-colonization, (2) hyphae $(\mathrm{H})$, (3) hyphae and vesicles $(\mathrm{H}+\mathrm{V}),(4)$ hyphae and arbuscules $(\mathrm{H}+\mathrm{A})$, (5) hyphae, vesicles and 
arbuscules $(\mathrm{H}+\mathrm{V}+\mathrm{A})$ [36]. The percentage of colonization and each mycorrhizal structure were calculated.

\subsection{Determination of Soil Acid Phosphatase}

One gram of soil was collected from the middle of the pot. The fresh soil was suspended in $4 \mathrm{~mL}$ of $5 \%(v / v)$ toluene and $0.5 \mathrm{~mL}$ of the soil supernatant was mixed with $0.4 \mathrm{~mL}$ of $200 \mathrm{mM}$ acetate buffer at pH 5.2 and $0.1 \mathrm{~mL}$ of $150 \mathrm{mM}$ PNPP disodium hexahydrate (TCI, Tokyo, Japan). The mixture was incubated at $37^{\circ} \mathrm{C}$ for $1 \mathrm{~h}$ before the reaction was stopped by adding $0.5 \mathrm{~mL}$ of $0.5 \mathrm{M} \mathrm{NaOH}$. Absorption at $410 \mathrm{~nm}$ was measured using a microplate reader (BIOTEX, PowerwaveX). The activity of acid phosphatase (nmol PNP/g soil FW/hour) was calculated using a p-nitrophenol (PNP) (200-2000 nmol/mL) standard.

\subsection{Data Analysis}

The data were visualized as box plots by the ggplot2 package [37] in R. Significant differences among the means of the treatments were analyzed by Student's $t$-test and One-way ANOVA following LSD by the agricolae package [38] in R.

\section{Results}

3.1. Acaulospora Is the Dominant AMF in Lowland Rice Roots under Non-Flooded and Flooded Conditions

Our previous study demonstrated that flooding reduced colonization and abundance of AMF in roots of rice seedlings grown in organic rice paddy soil [5]. To identify endophytic AMF in the rice roots, the rDNA sequences of rice roots grown in non-flooded and flooded conditions were amplified by Kruger primers and clustered into different OTUs with 97\% sequence similarity. To determine whether the numbers of clones sufficiently represented AMF diversity in the rice roots, we constructed rarefaction curves and their extrapolations (Figure 1A). In the two different gravimetric regimes, rarefaction curves for OTUs reached a plateau. The data suggest that the number of sequences provided full coverage of the AMF diversity. The total OTU numbers (richness) of the endophytic AMF rDNA were 21 OTUs, 13 OTUs were detected in the non-flooded condition, 12 OTUs in the flooded condition. The Shannon-Wiener diversity index $\left(\mathrm{H}^{\prime}\right)$ and AMF rDNA sequence evenness were higher in the non-flooded condition than in the flooded condition (Figure 1B). This result indicates that flooding reduces the diversity of AMF in rice roots. The representative OTU sequences were blasted in the NCBI database and these sequences were used for the subsequent phylogenetic analyses. The result revealed the presence of four Glomeromycotean genera in the rice roots, including Acaulospora, Dentiscutata, Glomus and Paraglomus. In rice roots grown in the non-flooded condition, the major AMF were Acaulospora and Dentiscutata, while in the flooded condition, Acaulospora was the most dominant genus. Moreover, Acaulospora OTU13-14 were relatively more abundant and were found in both the nonflooded and flooded conditions. Thus, they were considered the core AMF in the lowland rice paddy condition.

\subsection{Acaulospora Spores Are Propagated by Trap Culture}

We propagated the indigenous AMF spores in a greenhouse using a trap culture with a maize host (Figure 2A). Acaulospora spores were isolated and used for a monospore culture (Figure 2B). The cultured Acaulospora spores mounted in PVLG solution with and without Melzer's reagent were visualized under a microscope. The germinal wall of spores was stained red-purple by Melzer's reagent (Figure 2C,D). Finally, to confirm whether the cultured Acaulospora spores were the core AMF present in the rice roots, we analyzed the sequence similarity of the SSU-ITS-LSU sequences from spores with the representative Acaulospora OTUs. The result showed eight of the ten spore sequences shared sequence similarity at $98.4-99.4 \%$ with OTU13-14, which were the dominant AMF OTUs in the rice roots. The other two spore sequences showed the highest similarity, with OTU14 at 95\% (Figure 2E). The Acaulospora spore sequences were annotated with the NCBI database. They 
shared the highest identities with $A$. delicata in the range of 93.50-94.29\%, A. mellea in the range of $90.45-93.58 \%$ and $A$. rugosa in the range of $93.58-94.05$.

A

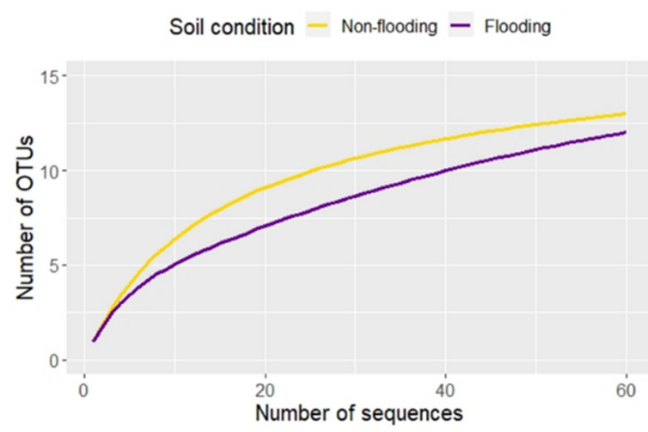

\begin{tabular}{|lcc|}
\multicolumn{3}{c}{ B } \\
\hline Diversity parameter & Non-flooding & Flooding \\
\hline Richness S & 13 & 12 \\
\hline Shannon's index H & 2.25 & 1.80 \\
\hline Evenness E & 0.89 & 0.72 \\
\hline
\end{tabular}

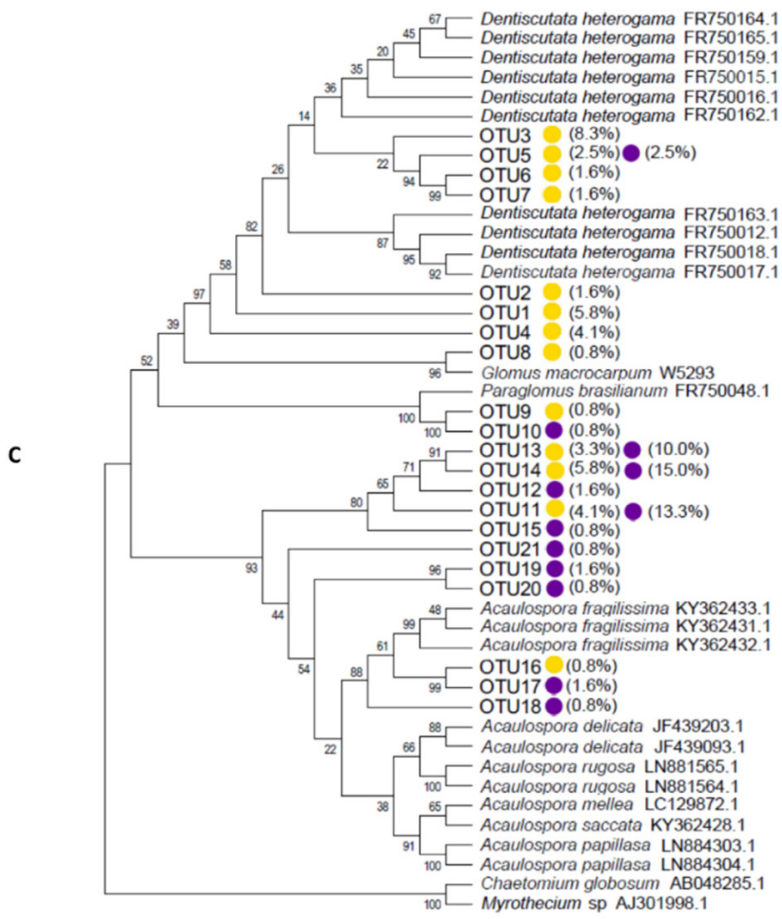

Figure 1. AMF OTUs detected in rice roots grown in non-flooded and flooded conditions. Rarefaction curves were analyzed from the SSU-ITS-LSU sequences of Glomeromycota amplified from rice roots grown in both conditions (A). Diversity indices between the two different conditions were summarized in Table (B). Phylotaxonomic analyses of representative AMF OTUs and their closest sequence similarity from the Maarjam and NCBI databases were constructed from the SSU-ITSLSU sequences of mycorrhizal rice roots grown under non-flooded $(\bullet)$ and flooded $(\bullet)$ conditions (1000 bootstrap). GenBank accessions are placed behind AMF species reported in the databases. Relative abundances of AMF OTUs are demonstrated in percent with parentheses (C).

\subsection{The Acaulospora Fungi Suppress Rice Seedling Growth but Not Photosynthetic Efficiency}

To characterize the biological function of the cultured Acaulospora fungi in rice, we grew Nipponbare rice seedlings in sterile soils with and without the Acaulospora inoculum for six weeks in the greenhouse. The soil used in this experiment contained $347.96 \mathrm{ppm}$ total nitrogen, $72.52 \mathrm{ppm}$ total $\mathrm{P}, 37.38 \mathrm{ppm}$ available $\mathrm{P}, 479.34 \mathrm{ppm}$ total $\mathrm{K}$ and $28.48 \mathrm{~g} / \mathrm{kg}$ organic matter. The soil $\mathrm{pH}$ and electrical conductivity were 7.08 and $0.24 \mathrm{ds} / \mathrm{m}$, respectively. Therefore, we considered this a fertile and P-sufficient soil. 


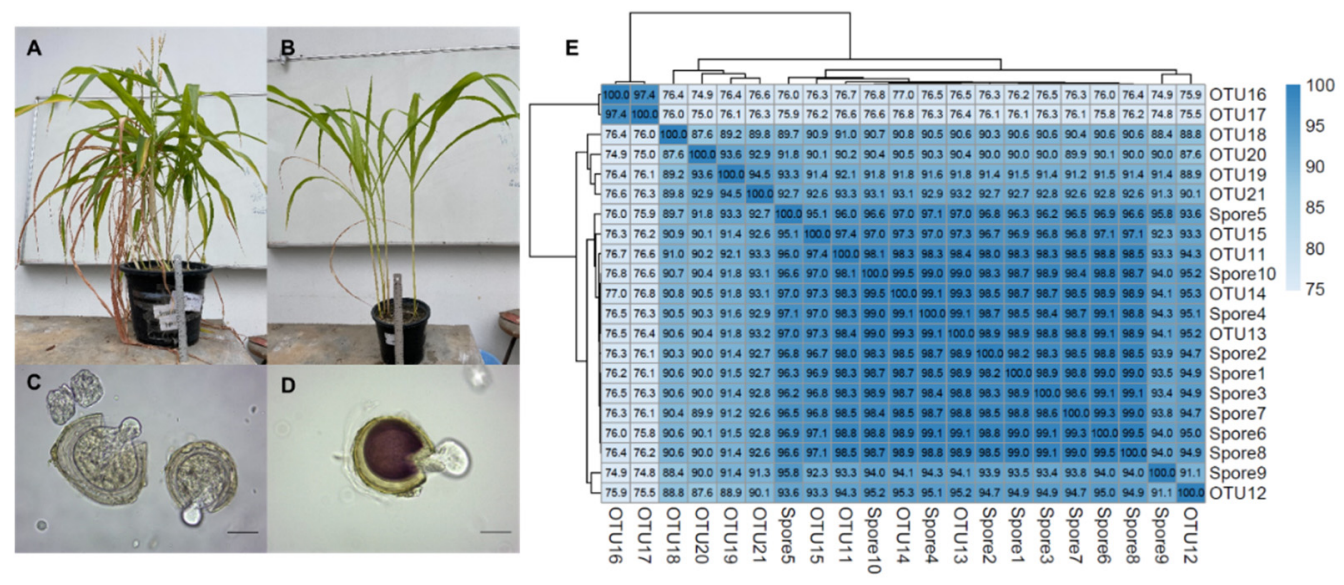

Figure 2. Trap culture of indigenous AMF spores. The trap culture using maize plants was prepared from organic rice paddy soil and sterile sand at a ratio of 1:3 (A). Later, Acaulospora spores were isolated based on their spore morphology for the monospore culture (B). The Acaulospora spores were mounted in polyvinyl alcohol-lactic acid-glycerol solution (C) and Melzer's reagent (D), visualized under a bright field microscope. Scale bars represent $30 \mu \mathrm{m}$. The heatmap displays percent similarity of the SSU-ITS-LSU sequences from the Acaulospora spores and the representative Acaulospora OTUs from the rice roots (dark blue represents most similar and light blue less similar) (E).

The AMF-inoculated roots were examined by Trypan blue staining and visualized under a microscope. Mycorrhizal structures such as hyphae, vesicle and arbuscule were detected in the roots of inoculated plants (Figure 3A,B). The AMF colonization and mycorrhization of rice roots were about $70 \%$ and $40 \%$, respectively (Figure $3 \mathrm{C}$ ). Our result showed that AMF inoculation reduced plant height (Figure 4A) and plant biomass (Figure 4B). It did not change shoot $\mathrm{P}$ concentration but significantly increased root $\mathrm{P}$ concentration (Figure 4C). However, AMF inoculation did not change the proportion of incoming light energy for photosynthesis (Figure 4C) and the relative chlorophyll content (Figure 4D). These results suggest that AMF inoculation suppresses the growth of rice seedlings but does not alter photosynthetic activities.
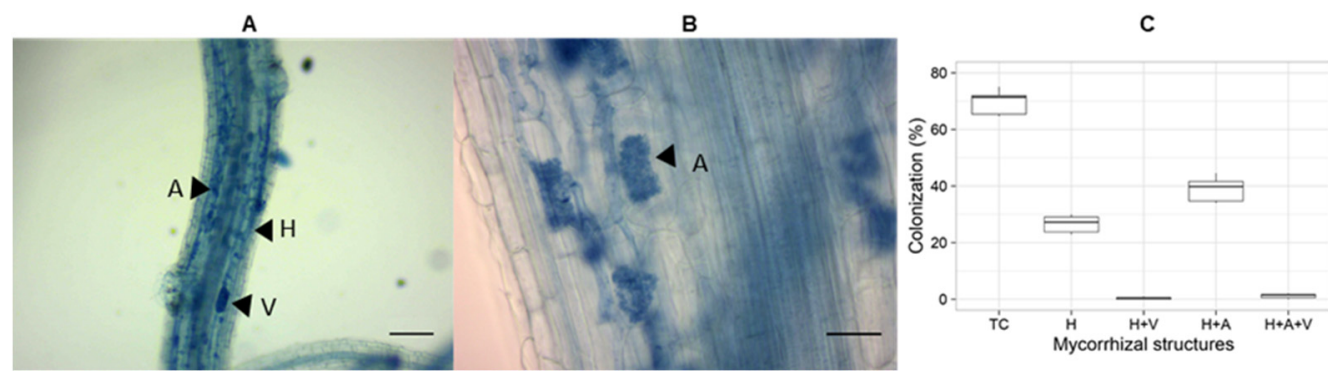

Figure 3. Photograph (A) shows the degree of colonization by Acaulospora fungi in AMF-inoculated roots of rice seedlings. Mycorrhizal roots containing various AMF structures were visualized under a bright field microscope. $\mathrm{H}, \mathrm{V}$, and A represent hypha, vesicle and arbuscule, respectively. The scale bar represents $100 \mu \mathrm{m}$. Photograph (B) shows mature arbuscules of Acaulospora fungi in the roots. The scale bar represents $30 \mu \mathrm{m}$. Degrees of AMF colonization were categorized into the following five groups: 1. Non-colonization, 2. Hyphae $(\mathrm{H}), 3$. Hyphae and vesicles $(\mathrm{H}+\mathrm{V}), 4$. Hyphae and arbuscules $(\mathrm{H}+\mathrm{A})$, and 5 . Hyphae, vesicles and arbuscules $(\mathrm{H}+\mathrm{V}+\mathrm{A})$. The box plots $(\mathrm{C})$ show the distribution of mycorrhizal structure ( $n=5$ biological replicates). 


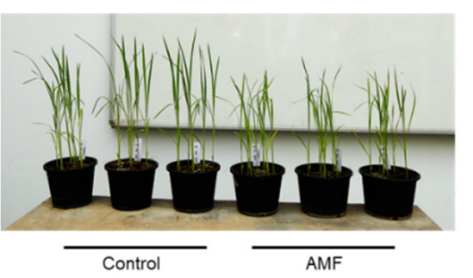

B

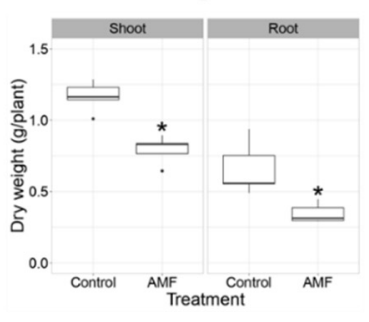

c
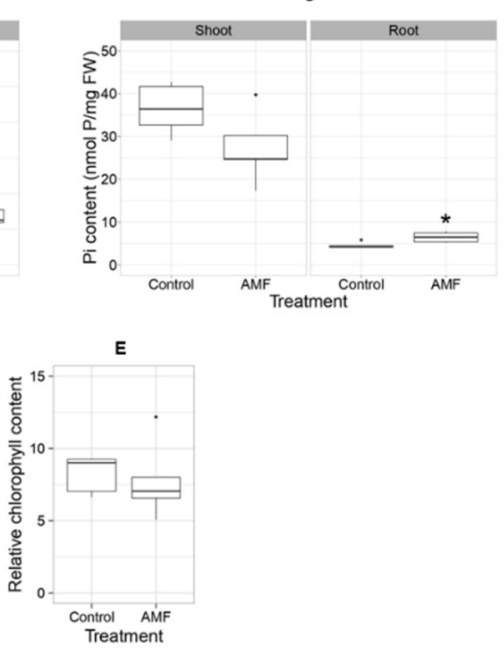

Figure 4. Effect of AMF inoculation on rice growth performance. Rice seedlings were grown for 6 weeks in sterile soil recolonized with a microbial wash (control) and with the Acaulospora inoculum (AMF) (A). The box plots show the distribution of shoot and root dry weight (B), shoot and root Pi content (C), fraction of incoming energy consisting of Phi2, PhiNPQ and PhiNO (D), and relative chlorophyll content $(\mathrm{E})(\mathrm{n}=5$ biological replicates). Statistical analysis was performed by Student's $t$-test. Asterisks indicate significant differences between the control plants and the AMF-treated plants $(p<0.05)$.

Inoculation with Acaulospora fungi improved soil $\mathrm{P}$ availability by enhancing soil acid phosphatase activities.

To determine the effect of Acaulospora AMF inoculation on soil P status, we measured total $\mathrm{P}$ content, available $\mathrm{P}$ and acid phosphatase activity in the non-inoculated and inoculated soils, and compared the data with the data from a blank treatment at the end of the experiment. The blank pots without rice seedlings contained the sterile soil recolonized with the microbial filtrate. The results showed that total P contents between the non-inoculated and inoculated soils were not different but lower than the total P content of the blank soil (Figure 5A). This suggested that some P in the soils was consumed by the rice seedlings. However, the AMF inoculation significantly increased the available P content (Figure 5B) and acid phosphatase activity (Figure 5C) in the soil. Thus, the presence of Acaulospora fungi in the soil improves soil $\mathrm{P}$ availability.

A

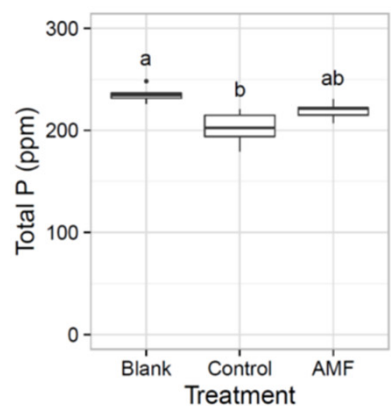

B

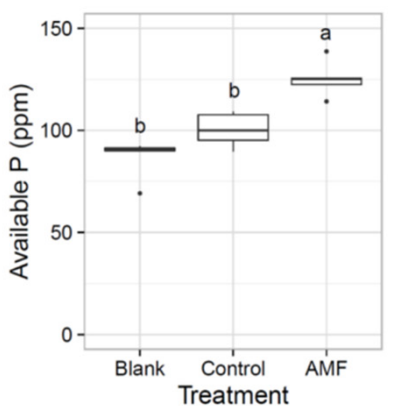

C

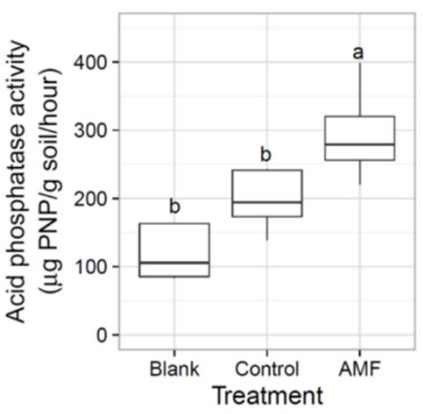

Figure 5. Effect of AMF inoculation on soil $P$ availability. The box plots show the distribution of total $\mathrm{P}(\mathrm{A})$, available $\mathrm{P}(\mathbf{B})$ and acid phosphatase activity $(\mathbf{C})$ in non-inoculated soil without rice seedlings (blank), non-inoculated soil (control) and AMF-inoculated soil (AMF) ( $\mathrm{n}=5$ biological replicates). Statistical analysis was performed by One-way ANOVA following LSD. Different letters indicate significant differences among the treatments $(p<0.05)$. 


\section{Discussion}

Based on the AMF sequences present in the roots of rice plants grown in non-flooded and flooded soil, flooding reduced the diversity of AMF in the roots (Figure 1B). The reduction of AMF diversity was related to the absence of Dentiscutata (Figure 1C). Dentiscutata OTU 1-7 shared the highest sequence similarity with Dentiscutata heterogama. Their sequence abundance was depleted in the flooded condition while Acaulospora OTU 11-24 were enriched. In a depressional wetland, Dentiscutata and Acaulospora are found in different hydrologic gradients. Dentiscutata heterogama is dominant in a predominantly dry zone while Acaulospora fungi are more often observed in an intermittent wet zone. Moreover, both of them rarely appear in a predominantly wet zone [39]. Furthermore, in coastal wetlands, their presence is dependent on the season. Dentiscutata heterogama is restricted in dry seasons while Acaulospora fungi are found in dry and rainy seasons [40]. Acaulospora species are thought to be relatively tolerant to flooding since they are reported as the dominant AMF and fungal genus in high-moisture soils [41,42]. These findings support the spatial existence of Dentiscutata heterogama and Acaulospora fungi in rice roots in non-flooded and flooded organic rice paddy soil.

Acaulospora fungi are the core AMF in the roots of rice grown in organic lowland rice paddies. While the colonization of AMF in roots was significantly reduced in flooded soil [5], Acaulospora fungi were found to be relatively more abundant than other indigenous endophytic AMF in rice roots (Figure 1C), and a higher abundance of Acaulospora fungi has been reported in some lowland rice paddies $[18,20]$. Although, the density of total AMF spores is relatively lower in lowland rice paddies, compared to midland and upland rice paddies, Acaulospora spores are the most abundant in lowland ecosystems. Up to $80 \%$ of AMF spores found in lowland rice paddy soils were from Acaulospora [20]. Therefore, in the present study, it is highly likely that the Acaulospora spores found in the organic lowland rice paddy soil were propagated by the trap cultures (Figure 2A,B).

Almost all of the cultured Acaulospora spore sequences shared sequence similarity at 98.4-99.4\% with the dominant AMF OTU13-14 in the rice roots, and the other two spore sequences showed the highest similarity with the OTU14 at 95\%. The cultured Acaulospora spores could be classified into two species based on the standard $97 \%$ sequence similarity for clustering of microbial rDNA sequences [43]. However, classification of AMF species using the rDNA gene sequence similarity threshold of $97 \%$ may overestimate the actual number of AMF species, especially when the sequences contain the ITS regions [44,45]. For example, the intra-genomic similarity in the ITS2 region from the ten rDNA paralogs of the Rhizophagus irregularis, a model AMF species, is $90.28 \%$ [45]. Thus, further identification of the cultured Acaulospora spores by AMF spore morphology will be performed.

To characterize the symbiotic functions of the cultured Acaulospora fungi, Nipponbare rice seedlings were inoculated with the Acaulospora inoculum. At 6 weeks post-inoculation, the AMF had colonized $70 \%$ of the rice roots and formed mature arbuscules (Figure 3C). This indicates the successful colonization of rice roots by AMF [46]. Compared with the noninoculated plants, AMF inoculation suppressed the growth of rice seedlings (Figure 4A,B) and did not promote accumulation of $\mathrm{P}$ in shoots (Figure $4 \mathrm{C}$ ). We speculate that the growth suppression due to AMF inoculation found in this study might be a result of the soil $\mathrm{P}$ condition. The available P content of the soil was $37.38 \mathrm{ppm}$, which is considered a high P level for rice seedlings [47]. This available $P$ concentration is generally found in lowland rice paddies [48,49]. In a high $\mathrm{P}$ condition, $\mathrm{AMF}$ symbiosis in rice roots was inhibited [2]. However, in our previous study, the addition of $\mathrm{P}$ in the soil did not affect the colonization of SMP rice roots by indigenous AMF [5]. In this study, the dominance of AMF from Acaulospora in the SMP rice roots may be due to a tolerance of high P soil. Some AMF species, including A. laevis, which can aggressively colonize roots in P-deficient soils are also capable of intensively colonizing roots in P-sufficient soils, but they reduce the growth of host plants and do not enhance plant $\mathrm{P}$ uptake [50]. In addition, $\mathrm{P}$ fertilization promotes the parasitic relationship between AMF and host plants, which lowers the biomass of the mycorrhizal plants [51]. However, in our study, the parasitism between the mycorrhizal Nipponbare rice 
seedlings and the Acaulospora AMF did not reduce photosynthetic efficiency in the leaves (Figure 4D,E). This behavior is unlike behaviors observed in certain other plants infected by fungal root parasites such as Fusarium oxysporum and Setophoma terrestris [52,53]. Growth suppression of rice seedlings by Acaulospora AMF might be a response to an imbalance between the cost and benefit experienced during the AMF-plant interaction.

To clarify the effect of AMF inoculation on soil P availability, a blank treatment was included in the experiment using sterile soil without rice seedlings or AMF inoculum. Compared with the control and AMF treatments, the blank soils contained the highest level of total P but the lowest level of available P (Figure 5A,B). AMF inoculation significantly increased the amount of available $\mathrm{P}$ and the acid phosphatase activity in the soil (Figure 5B,C). The reduction of total $\mathrm{P}$ in the soils was due to $\mathrm{P}$ uptake by the rice seedlings. Rice seedlings increased the amount of available P in non-inoculated and inoculated soil since rice roots exude acid phosphatase, which increases soil P solubility [54]. Moreover, the genes involved in acid phosphatase secretion in the host plants are up-regulated by AMF symbiosis, which increases the release of acid phosphatase from mycorrhizal roots. AMF are also able to directly release acid phosphatases from their hyphae into the soil [55]. These findings strongly indicate that Acaulospora AMF improve soil P availability by increasing acid phosphatase activity in the soil.

\section{Conclusions}

Acaulospora fungi were the core arbuscular mycorrhizal fungi in lowland rice roots grown in organic rice paddy soil. They improved P mobilization by enhancing the release of acid phosphatase in the soil. In rainfed lowland rice cultivation, especially by direct seeding of rice, rice seeds are sown in non-flooded fields, allowing the seedlings to transiently form a symbiosis with indigenous arbuscular mycorrhizal fungi. After the rice seedlings are flooded, arbuscular mycorrhizal fungal colonization and symbiosis are arrested. Thus, the usual suppression of growth by Acaulospora fungi in the P-sufficient condition is prevented at the beginning of rice growth and development. However, the existence of Acaulospora fungi could accelerate the $\mathrm{P}$ mineralization of rice paddies, leading to more available $\mathrm{P}$ in the soil, which is essential for the growth of lowland rice.

Author Contributions: Conceptualization, K.N. and L.K.; methodology, K.N., P.R. and L.K.; software, K.N. and L.K.; validation, K.N. and L.K.; formal analysis, K.N. and L.K.; investigation, K.N. and L.K.; resources, K.N. and L.K.; data curation, K.N. and L.K.; writing-original draft preparation, K.N. and L.K.; writing-review and editing, L.K.; visualization, K.N. and L.K.; supervision, P.R. and L.K.; project administration, L.K.; funding acquisition, K.N. and L.K. All authors have read and agreed to the published version of the manuscript.

Funding: This research was supported by the National Science, Research and Innovation Fund (NSRF) and Prince of Songkla University, Grant No. SCI6505179a (to L.K.), and by a research assistantship from the Faculty of Science, Prince of Songkla University, Contract no.1-2563-02-001 (to K.N.).

Institutional Review Board Statement: Not applicable.

Informed Consent Statement: Not applicable.

Data Availability Statement: Request to corresponding author of this article.

Acknowledgments: The authors are thankful to Supachitra Chadchawan, Chulalongkorn University, Thailand for providing rice germplasms, to Soawapa Duangpan for the use of MultispeQ fluorometer and to Phatthalung Rice Research Center, Phatthalung, Thailand for providing soil from organic rice paddies.

Conflicts of Interest: The authors declare no conflict of interest. 


\section{References}

1. Wang, S.; Chen, A.; Xie, K.; Yang, X.; Luo, Z.; Chen, J.; Zeng, D.; Ren, Y.; Yang, C.; Wang, L.; et al. Functional analysis of the OsNPF4.5 nitrate transporter reveals a conserved mycorrhizal pathway of nitrogen acquisition in plants. Proc. Natl. Acad. Sci. USA 2020, 117, 16649-16659. [CrossRef]

2. Kobae, Y.; Ohmori, Y.; Saito, C.; Yano, K.; Ohtomo, R.; Fujiwara, T. Phosphate Treatment Strongly Inhibits New Arbuscule Development But Not the Maintenance of Arbuscule in Mycorrhizal Rice Roots. Plant Physiol. 2016, 171, 566-579. [CrossRef]

3. Zhang, S.; Rasool, G.; Guo, X.; Sen, L.; Cao, K. Effects of Different Irrigation Methods on Environmental Factors, Rice Production, and Water Use Efficiency. Water 2020, 12, 2239. [CrossRef]

4. Vallino, M.; Fiorilli, V.; Bonfante, P. Rice flooding negatively impacts root branching and arbuscular mycorrhizal colonization, but not fungal viability. Plant Cell Environ. 2014, 37, 557-572. [CrossRef]

5. Klinnawee, L.; Noirungsee, N.; Nopphakat, K.; Runsaeng, P.; Chantarachot, T. Flooding overshadows phosphorus availability in controlling the intensity of arbuscular mycorrhizal colonization in Sangyod Muang Phatthalung lowland indica rice. ScienceAsia 2021, 47, 1-9. [CrossRef]

6. Chialva, M.; Ghignone, S.; Cozzi, P.; Lazzari, B.; Bonfante, P.; Abbruscato, P.; Lumini, E. Water management and phenology influence the root-associated rice field microbiota. FEMS Microbiol. Ecol. 2020, 96, 96. [CrossRef] [PubMed]

7. Wang, Y.; Li, T.; Li, Y.; Björn, L.O.; Rosendahl, S.; Olsson, P.A.; Li, S.; Fu, X. Community dynamics of arbuscular mycorrhizal fungi in high-input and intensively irrigated rice cultivation systems. Appl. Environ. Microbiol. 2015, 81, 2958-2965. [CrossRef]

8. Watanarojanaporn, N.; Boonkerd, N.; Tittabutr, P.; Longtonglang, A.; Young, J.P.W.; Teaumroong, N. Effect of rice cultivation systems on indigenous arbuscular mycorrhizal fungal community structure. Microbes Environ. 2013, 28, 316-324. [CrossRef] [PubMed]

9. Chang, J.; Sun, Y.; Tian, L.; Ji, L.; Luo, S.; Nasir, F.; Kuramae, E.E.; Tian, C. The Structure of Rhizosphere Fungal Communities of Wild and Domesticated Rice: Changes in Diversity and Co-occurrence Patterns. Front. Microbiol. 2021, 12, 45. [CrossRef]

10. Wang, Y.; Bao, X.; Li, S. Effects of Arbuscular Mycorrhizal Fungi on Rice Growth Under Different Flooding and Shading Regimes. Front. Microbiol. 2021, 12, 3276. [CrossRef]

11. Andrino, A.; Guggenberger, G.; Sauheitl, L.; Burkart, S.; Boy, J. Carbon investment into mobilization of mineral and organic phosphorus by arbuscular mycorrhiza. Biol. Fertil. Soils 2021, 57, 47-64. [CrossRef]

12. Sato, T.; Hachiya, S.; Inamura, N.; Ezawa, T.; Cheng, W.; Tawaraya, K. Secretion of acid phosphatase from extraradical hyphae of the arbuscular mycorrhizal fungus Rhizophagus clarus is regulated in response to phosphate availability. Mycorrhiza 2019, 29, 599-605. [CrossRef]

13. Wang, X.-X.; Hoffland, E.; Feng, G.; Kuyper, T.W. Phosphate Uptake from Phytate Due to Hyphae-Mediated Phytase Activity by Arbuscular Mycorrhizal Maize. Front. Plant Sci. 2017, 8, 684. [CrossRef] [PubMed]

14. Zhang, S.; Guo, X.; Yun, W.; Xia, Y.; You, Z.; Rillig, M.C. Arbuscular mycorrhiza contributes to the control of phosphorus loss in paddy fields. Plant Soil 2020, 447, 623-636. [CrossRef]

15. Zhang, S.; Wang, L.; Ma, F.; Zhang, X.; Fu, D. Reducing nitrogen runoff from paddy fields with arbuscular mycorrhizal fungi under different fertilizer regimes. J. Environ. Sci. 2016, 46, 92-100. [CrossRef]

16. Chareesri, A.; De Deyn, G.B.; Sergeeva, L.; Polthanee, A.; Kuyper, T.W. Increased arbuscular mycorrhizal fungal colonization reduces yield loss of rice (Oryza sativa L.) under drought. Mycorrhiza 2020, 30, 315-328. [CrossRef] [PubMed]

17. Parvin, S.; Van Geel, M.; Yeasmin, T.; Lievens, B.; Honnay, O. Variation in arbuscular mycorrhizal fungal communities associated with lowland rice (Oryza sativa) along a gradient of soil salinity and arsenic contamination in Bangladesh. Sci. Total Environ. 2019, 686, 546-554. [CrossRef]

18. Sarkodee-Addo, E.; Yasuda, M.; Gyu Lee, C.; Kanasugi, M.; Fujii, Y.; Omari, R.A.; Abebrese, S.O.; Bam, R.; Asuming-Brempong, S.; Dastogeer, K.M.G.; et al. Arbuscular Mycorrhizal Fungi Associated with Rice (Oryza sativa L.) in Ghana: Effect of Regional Locations and Soil Factors on Diversity and Community Assembly. Agronomy 2020, 10, 559. [CrossRef]

19. Baki, M.Z.I.; Suzuki, K.; Takahashi, K.; Chowdhury, S.A.; Asiloglu, R.; Harada, N. Molecular genetic characterization of arbuscular mycorrhizal fungi associated with upland rice in Bangladesh. Rhizosphere 2021, 18, 100357. [CrossRef]

20. Martins, W.F.X.; Rodrigues, B.F. Identification of dominant arbuscular mycorrhizal fungi in different rice ecosystems. Agric. Res. 2020, 9, 46-55. [CrossRef]

21. Kruger, M.; Stockinger, H.; Kruger, C.; Schussler, A. DNA-based species level detection of Glomeromycota: One PCR primer set for all arbuscular mycorrhizal fungi. New Phytol. 2009, 183, 212-223. [CrossRef] [PubMed]

22. Madeira, F.; Park, Y.M.; Lee, J.; Buso, N.; Gur, T.; Madhusoodanan, N.; Basutkar, P.; Tivey, A.R.N.; Potter, S.C.; Finn, R.D.; et al The EMBL-EBI search and sequence analysis tools APIs in 2019. Nucleic Acids Res. 2019, 47, W636-W641. [CrossRef] [PubMed]

23. Jombart, T. Adegenet: A R package for the multivariate analysis of genetic markers. Bioinformatics 2008, 24, 1403-1405. [CrossRef]

24. Wilkinson, S. Kmer: An R Package for Fast Alignment-Free Clustering of Biological Sequences; R Foundation for Statistical Computing: Vienna, Austria, 2018.

25. Oksanen, J.; Blanchet, F.G.; Kindt, R.; Legendre, P.; Minchin, P.; O'Hara, R.B.; Simpson, G.; Solymos, P.; Stevenes, M.H.H.; Wagner, H. Vegan: Community Ecology Package; R Package Version 2.4-6; R Foundation for Statistical Computing: Vienna, Austria, 2018.

26. Kumar, S.; Stecher, G.; Li, M.; Knyaz, C.; Tamura, K. MEGA X: Molecular Evolutionary Genetics Analysis across Computing Platforms. Mol. Biol. Evol. 2018, 35, 1547-1549. [CrossRef] [PubMed] 
27. Gerdemann, J.W.; Nicolson, T.H. Spores of mycorrhizal Endogone species extracted from soil by wet sieving and decanting. Trans. Br. Mycol. Soc. 1963, 46, 235-244. [CrossRef]

28. Charif, D.; Lobry, J.R. SeqinR 1.0-2: A Contributed Package to the R Project for Statistical Computing Devoted to Biological Sequences Retrieval and Analysis BT. In Structural Approaches to Sequence Evolution: Molecules, Networks, Populations; Bastolla, U., Porto, M., Roman, H.E., Vendruscolo, M., Eds.; Springer: Berlin/Heidelberg, Germany, 2007; pp. 207-232, ISBN 978-3-540-35306-5.

29. Kolde, R. Pheatmap: Pretty Heatmaps, R Package Version 1.2; R Foundation for Statistical Computing: Vienna, Austria, 2012.

30. Walkley, A.; Black, I.A. An examination of the degtjareff method for determining soil organic matter, and a proposed modification of the chromic acid titration method. Soil Sci. 1934, 37, 29-38. [CrossRef]

31. AOAC International. AOAC Official Method 958.01. In Official Methods of Analysis of AOAC International; Kane, P.F., Ed.; AOAC International: Rockville, MD, USA, 2016; p. 6.

32. AOAC International. AOAC Official Method 970.01. In Official Methods of Analysis of AOAC International; Kane, P.F., Ed.; AOAC International: Rockville, MD, USA, 2016; p. 9.

33. AOAC International. AOAC Official Method 983.02. In Official Methods of Analysis of AOAC International; Kane, P.F., Ed.; AOAC International: Rockville, MD, USA, 2016; pp. 23-26.

34. Kuhlgert, S.; Austic, G.; Zegarac, R.; Osei-Bonsu, I.; Hoh, D.; Chilvers, M.I.; Roth, M.G.; Bi, K.; TerAvest, D.; Weebadde, P.; et al MultispeQ Beta: A tool for large-scale plant phenotyping connected to the open PhotosynQ network. R. Soc. Open Sci. 2016, 3, 160592. [CrossRef] [PubMed]

35. Hurry, V.; Strand, A.; Furbank, R.; Stitt, M. The role of inorganic phosphate in the development of freezing tolerance and the acclimatization of photosynthesis to low temperature is revealed by the pho mutants of Arabidopsis thaliana. Plant J. 2000, 24, 383-396. [CrossRef]

36. Ho-Plágaro, T.; Tamayo-Navarrete, M.I.; García-Garrido, J.M. Histochemical Staining and Quantification of Arbuscular Mycorrhizal Fungal Colonization BT. In Arbuscular Mycorrhizal Fungi: Methods and Protocols; Ferrol, N., Lanfranco, L., Eds.; Springer: New York, NY, USA, 2020; pp. 43-52. ISBN 978-1-0716-0603-2.

37. Wickham, H. ggplot2: Elegant Graphics for Data Analysis; Springer International Publishing: Cham, Switzerland, 2016; ISBN 978-3-319-24277-4.

38. Mendiburu, F.D. Agricolae: Statistical Procedures for Agricultural Research; R Package Version 1.2-3; R Foundation for Statistical Computing: Vienna, Austria, 2015.

39. Miller, S.P.; Bever, J.D. Distribution of Arbuscular Mycorrhizal Fungi in Stands of the Wetland Grass Panicum hemitomon along a Wide Hydrologic Gradient. Oecologia 1999, 119, 586-592. [CrossRef]

40. Fabián, D.; Guadarrama, P.; Hernadez-Cuevas, L.; Ramos-Zapata, J.A. Arbuscular mycorrhizal fungi in a coastal wetland in Yucatan, Mexico. Bot. Sci. 2018, 96, 24-34. [CrossRef]

41. Asano, K.; Kagong, W.V.; Mohammad, S.M.; Sakazaki, K.; Talip, M.S.; Sahmat, S.S.; Chan, M.K.; Isoi, T.; Kano-Nakata, M.; Ehara, H. Arbuscular Mycorrhizal Communities in the Roots of Sago Palm in Mineral and Shallow Peat Soils. Agriculture 2021, 11, 1161. [CrossRef]

42. Yang, Z.; Shi, Y.; Wang, J.; Wang, L.; Li, X.; Zhang, D. Unique functional responses of fungal communities to various environments in the mangroves of the Maowei Sea in Guangxi, China. Mar. Pollut. Bull. 2021, 173, 113091. [CrossRef] [PubMed]

43. Stackebrandt, E.; Goebel, B.M. Taxonomic Note: A Place for DNA-DNA Reassociation and 16S rRNA Sequence Analysis in the Present Species Definition in Bacteriology. Int. J. Syst. Evol. Microbiol. 1994, 44, 846-849. [CrossRef]

44. House, G.L.; Ekanayake, S.; Ruan, Y.; Schütte, U.M.E.; Kaonongbua, W.; Fox, G.; Ye, Y.; Bever, J.D. Phylogenetically Structured Differences in rRNA Gene Sequence Variation among Species of Arbuscular Mycorrhizal Fungi and Their Implications for Sequence Clustering. Appl. Environ. Microbiol. 2016, 82, 4921-4930. [CrossRef]

45. Maeda, T.; Kobayashi, Y.; Kameoka, H.; Okuma, N.; Takeda, N.; Yamaguchi, K.; Bino, T.; Shigenobu, S.; Kawaguchi, M. Evidence of non-tandemly repeated rDNAs and their intragenomic heterogeneity in Rhizophagus irregularis. Commun. Biol. 2018, 1, 87. [CrossRef]

46. Gutjahr, C.; Paszkowski, U. Multiple Control Levels of Root System Remodeling in Arbuscular Mycorrhizal Symbiosis. Front. Plant Sci. 2013, 4, 204. [CrossRef]

47. Pinit, S.; Chadchawan, S.; Chaiwanon, J. A simple high-throughput protocol for the extraction and quantification of inorganic phosphate in rice leaves. Appl. Plant Sci. 2020, 8, e11395. [CrossRef]

48. Uwasawa, M.; Sangtong, P.; Cholitkul, W. Behavior of phosphorus in paddy soils of Thailand. Soil Sci. Plant Nutr. 1988, $34,41-53$. [CrossRef]

49. Phairat, P.; Toru, M. The status of phosphorus in Thai soils and P evaluation using EDTA-NaF extraction method. Songklanakarin J. Sci. Technol. 2003, 25, 423-434.

50. Graham, J.H.; Abbott, L.K. Wheat responses to aggressive and non-aggressive arbuscular mycorrhizal fungi. Plant Soil 2000, 220, 207-218. [CrossRef]

51. Friede, M.; Unger, S.; Hellmann, C.; Beyschlag, W. Conditions Promoting Mycorrhizal Parasitism Are of Minor Importance for Competitive Interactions in Two Differentially Mycotrophic Species. Front. Plant Sci. 2016, 7, 1465. [CrossRef] [PubMed]

52. Ye, S.F.; Yu, J.Q.; Peng, Y.H.; Zheng, J.H.; Zou, L.Y. Incidence of Fusarium wilt in Cucumis sativus L. is promoted by cinnamic acid, an autotoxin in root exudates. Plant Soil 2004, 263, 143-150. [CrossRef] 
53. Sayago, P.; Juncosa, F.; Orio, A.G.A.; Luna, D.F.; Molina, G.; Lafi, J.; Ducasse, D.A. Bacillus subtilis ALBA01 alleviates onion pink root by antagonizing the pathogen Setophoma terrestris and allowing physiological status maintenance. Eur. J. Plant Pathol. 2020, 157, 509-519. [CrossRef]

54. Deng, S.; Lu, L.; Li, J.; Du, Z.; Liu, T.; Li, W.; Xu, F.; Shi, L.; Shou, H.; Wang, C. Purple acid phosphatase 10c encodes a major acid phosphatase that regulates plant growth under phosphate-deficient conditions in rice. J. Exp. Bot. 2020, 71, 4321-4332. [CrossRef] [PubMed]

55. Sato, T.; Ezawa, T.; Cheng, W.; Tawaraya, K. Release of acid phosphatase from extraradical hyphae of arbuscular mycorrhizal fungus Rhizophagus clarus. Soil Sci. Plant Nutr. 2015, 61, 269-274. [CrossRef] 